\title{
Earth's Earliest Atmospheres
}

\author{
Kevin Zahnle ${ }^{1}$, Laura Schaefer ${ }^{2}$, and Bruce Fegley ${ }^{2}$ \\ ${ }^{1}$ Space Science Division, NASA Ames Research Center, MS 245-3, Moffett Field, California 94035 \\ ${ }^{2}$ Planetary Chemistry Laboratory, Department of Earth and Planetary Sciences and McDonnell Center for the \\ Space Sciences, Washington University, St Louis, Missouri 63130 \\ Correspondence: kevin.j.zahnle@nasa.gov
}

\begin{abstract}
Earth is the one known example of an inhabited planet and to current knowledge the likeliest site of the one known origin of life. Here we discuss the origin of Earth's atmosphere and ocean and some of the environmental conditions of the early Earth as they may relate to the origin of life. A key punctuating event in the narrative is the Moon-forming impact, partly because it made Earth for a short time absolutely uninhabitable, and partly because it sets the boundary conditions for Earth's subsequent evolution. If life began on Earth, as opposed to having migrated here, it would have done so after the Moon-forming impact. What took place before the Moon formed determined the bulk properties of the Earth and probably determined the overall compositions and sizes of its atmospheres and oceans. What took place afterward animated these materials. One interesting consequence of the Moon-forming impact is that the mantle is devolatized, so that the volatiles subsequently fell out in a kind of condensation sequence. This ensures that the volatiles were concentrated toward the surface so that, for example, the oceans were likely salty from the start. We also point out that an atmosphere generated by impact degassing would tend to have a composition reflective of the impacting bodies (rather than the mantle), and these are almost without exception strongly reducing and volatile-rich. A consequence is that, although CO- or methane-rich atmospheres are not necessarily stable as steady states, they are quite likely to have existed as long-lived transients, many times. With CO comes abundant chemical energy in a metastable package, and with methane comes hydrogen cyanide and ammonia as important albeit less abundant gases.
\end{abstract}

$T^{\mathrm{h}}$ he origin of life has not been seen in Earth's rock record, and poor preservation of Earth's oldest rocks suggests that it will not be. The oldest bits of rock that might plausibly retain geochemical hints of habitable conditions on Earth's surface-a handful of zirconshave been subject to fierce debates regarding whether they contain such evidence. However, the weight of evidence does suggest that Earth has supported microbial life since the Hadean ("Hadean" refers to the geologic Eon preceding the Achaean. It can be regarded as Earth before the appearance of a true-rock record 3.9 $\mathrm{Ga}$ - the precise definition remains to be

Editors: David Deamer and Jack W. Szostak

Additional Perspectives on The Origins of Life available at www.cshperspectives.org

Copyright (C) 2010 Cold Spring Harbor Laboratory Press; all rights reserved; doi: 10.1101/cshperspect.a004895

Cite this article as Cold Spring Harb Perspect Biol 2010;2:a004895 
agreed on by the proper authorities). This would make Hadean Earth the one known planet where life has begun.

The modern focus on the atmosphere as the source of prebiotic chemistry dates to the famous Miller-Urey experiments of the 1950s (Miller 1953, 1955; Miller and Urey 1959; Oró and Kamel 1961; Johnson et al. 2008). These experiments were intended to model the kinds of disequilibrium chemistry that would have resulted from electrical discharges in, or ultraviolet radiation being absorbed in, highly reduced atmospheres in which methane, ammonia, and water were all major constituents. These experiments were driven by Harold C. Urey's theory that Earth accreted as a cool body and that its atmosphere was dominated by hydrogen and the hydrides of common volatiles (Urey won the Nobel Prize for Chemistry in 1934 for the discovery of deuterium). Miller and his colleagues, and many other investigators who have since performed similar experiments, have consistently found that a wide range of amino acids and other prebiotically interesting molecules form readily in such environments (e.g., see the review by Oró et al. 1990). These experiments were very influential in directing the attention of prebiotic chemists to a highly reduced primordial atmosphere.

However, photochemical studies showed that any methane (Lasaga et al. 1971) or ammonia (Kuhn and Atreya 1979; Kasting 1982) in the atmosphere would quickly be destroyed. Meanwhile geologically based arguments, which treat the atmosphere as outgassed from the solid Earth, were taken as strongly suggesting that Earth's original atmosphere was composed mostly of $\mathrm{H}_{2} \mathrm{O}, \mathrm{CO}_{2}$, and $\mathrm{N}_{2}$, with only small amounts of $\mathrm{CO}$ and $\mathrm{H}_{2}$, and essentially no $\mathrm{CH}_{4}$ or $\mathrm{NH}_{3}$ (Poole 1951; Holland 1962; Abelson 1966; Holland 1984). This composition of volcanic gases is determined by temperature and the QFM (quartz-fayalite-magnetite) mineral buffer pertinent to the modern mantle. Nor is there evidence of a time on Earth when things were clearly different. Geochemical evidence in Earth's oldest igneous rocks indicates that the redox state of the Earth's mantle has not changed over the past 3.8 Gyr (Delano
2001; Canil 2002). Miller-Urey-type experiments performed in the more oxidized mixtures of modern volcanic gases generate relatively little of prebiotic interest, especially when $\mathrm{CO}_{2}$ is abundant (Miller and Urey 1959; Schlessinger and Miller 1983; Stribling and Miller 1987). New work suggests that spark yields of ammonia, $\mathrm{HCN}$, and amino acids in $\mathrm{CO}_{2}$ - $\mathrm{N} 2$-water mixtures can be less disappointing if the water is allowed to become acidic (Cleaves et al. 2008). Nevertheless, the contrast between methane and ammonia on the one hand and carbon dioxide and dinitrogen on the other led many prebiotic chemists, Miller and Urey prominent among them, to regard the presence of life on Earth as providing a strong boundary condition on the nature of Earth's early atmosphere.

The sense of poor prospects led some to abandon the atmosphere in favor of the hydrosphere. At the low temperatures and high water activities of hydrothermal systems, it is in theory possible to get non-negligable amounts of methane and ammonia at the QFM buffer (French 1966; Shock and Schulte 1990, 1998). Shock and Schulte (1990) used this approach to explain the abundances of organic molecules in asteroids (as sampled by carbonaceous meteorites) and suggested that such a model might have application to the origin of life on Earth (Shock 1990; Shock et al. 1995; Shock and Schulte 1998). The issue of a submarine (as opposed to a subaerial) origin of life became contentious (Miller and Bada 1988, 1993; Shock and Schulte 1993). Significant features of the hydrothermal hypothesis are that (1) it ties the origin of life to the process of making organic molecules, and (2) it implies that life is widespread in the Solar System, because hydrothermal systems may exist in many moons (Shock and McKinnon 1993).

Another workaround is to abandon the idea that organic molecules were generated in situ here on Earth. Instead the organic molecules would be delivered by comets and asteroids and interplanetary dust particles (IDPs, Anders 1989; Chyba and Sagan 1992; Whittet 1997). The basis of this proposal is that organic molecules are abundant in the Solar System. Many meteorites and dust grains are rich in complex 
organic molecules, and there is little doubt that comets are at least as rich. The chief difficulty is that, apart from special cases, only a small fraction of the more interesting and more delicate organic materials in comets and asteroids would survive impact (Clark 1988; Anders 1989; Chyba et al. 1990; Chyba and Sagan 1992; Whittet 1997; Pierazzo and Chyba 1999; Pasek and Lauretta 2008). The importance of an exogenic source of organics to the origin of life has probably been overstated. In the median case the quantities aren't large and the biological potential of a modest cosmic windfall of IDPs is unclear, although a slow soft collision by a big organic-rich comet-possible but by construction unlikely_could have a huge unique effect (Clark 1988). An alternative lesson to be taken from abundant organics in the Solar System is that organic molecules are not hard to make, and so were probably also made here.

A third perspective to the origin of the atmosphere-that the earliest atmosphere was degassed from impacting material as it arrived rather than outgassed from the solid Earth into a primordial vacuum (Arrhenius et al 1974; Lange et al. 1985; Tyburczy et al. 1986; Abe and Matsui 1986; Zahnle et al. 1988; Ahrens et al. 1989)-has gotten comparatively little traction. Recently three new theoretical studies (Schaefer and Fegley 2007, 2010; Hashimoto et al. 2007) show that atmospheres dominated by impact degassing would be much more reduced than atmospheres dominated by Earth's mantle. A fourth recent study (Sugita and Schultz 2009) addresses impact degassing and impact synthesis in possible cometary matter experimentally. The latter can be regarded as parallel to the experiments performed by nature when the pieces of comet Shoemaker-Levy 9 struck Jupiter in July 1994. The SL9 impacts generated vast quantities of small molecules, especially CO, but the list of apparently synthetic products also included $\mathrm{HCN}, \mathrm{C}_{2} \mathrm{H}_{2}$, $\mathrm{C}_{2} \mathrm{H}_{4}, \mathrm{~S}_{2}, \mathrm{CS}, \mathrm{CS}_{2}, \mathrm{OCS}$, and $\mathrm{CO}_{2}$ (Zahnle et al. 1995; Harrington et al. 2004).

Here we address the state and properties of Earth's primordial atmosphere. Our review is presented in three parts: the origin of the atmosphere, the Moon-forming impact, and events taking place after the Moon-forming impact. Placing the origin of the atmosphere before the Moon-forming impact is a choice that is founded on the high volatile contents of all known chondritic meteorites: To build Earth without volatiles is difficult if all known examples of possible source materials are more volatile-rich than Earth. Nonetheless we will also consider the alternative-volatile delivery after the Moon-forming impact-because it is one of the concepts in debate (cf. Albarède 2009) and because the hypothesis of transient, strongly reduced impact-degassed atmospheres applies obviously and directly to it.

\section{BACKGROUND}

\section{Before the Moon-forming Impact: Origin of Planets and Atmospheres}

The origin of Earth's atmosphere is a profound question of comparative planetology. The basic alternatives are a primary atmosphere captured from the solar nebula or a secondary atmosphere degassed from condensed materials accreted by Earth. Although the debate has long appeared settled in favor of secondary atmospheres, primary atmospheres probably did exist and may have had a minor role to play.

Primary atmospheres are by defnition composed of gases captured from the solar nebula (Hayashi et al. 1979; Lewis and Prinn 1984; Ikoma and Genda 2006). In this model planetesimals (the first generation of solid worlds to form in the nebula) and proto-planets (the stage of growth between planetesimals and planets) capture nebular gases by gravitational attraction. The process is therefore much more efficient if the protoplanet is massive and the nebula cool. The captured gas is mostly $\mathrm{H}_{2}$ by far the most abundant element in the Universe-and interesting volatiles would tend to have been present as simple hydrides $\left(\mathrm{H}_{2} \mathrm{O}\right.$, $\mathrm{CH}_{4}, \mathrm{NH}_{3}$ ). Such atmospheres are common. Jupiter, Saturn, Uranus, and Neptune are examples of big ones.

To the extent that the planetesimals and proto-planets that accumulated to make the 
Earth did so inside the nebula, they too would have been immersed in primary $\mathrm{H}_{2}$-rich atmospheres. There is very little evidence left of Earth's primary atmosphere. It is possible that ${ }^{3} \mathrm{He}$ in the mantle is a fossil of the primary atmosphere, but the very low abundances of the noble gases relative to chemically reactive volatile elements such as carbon, hydrogen, nitrogen, and sulfur indicates that they have had profoundly different histories. The difference is nicely illustrated by nitrogen and neon. Nitrogen is the most volatile element other than hydrogen and the noble gases. Nitrogen and neon have very similar solar abundances and therefore would have been about equally abundant in the solar nebula, and they have similar atomic weights and so are comparably subject to escape, but in Earth's atmosphere the $\mathrm{Ne} / \mathrm{N}$ ratio is just $10^{-5}$. Likewise, argon and sulfur have similar solar abundances and capture of solar nebula gas would give a terrestrial Ar/S abundance ratio of $\sim 0.2$ instead of 0.00003 as observed.

When the solar nebula disappears the primary atmosphere escapes. Although escape of a primary atmosphere from a planet the size of Earth is difficult (Sekiya et al. 1980, 1981), escape is easy if the planet or planetesimal is the size of Mars or smaller: the first collision between two such planetesimals will raise the thermal velocities of a hydrogen-rich atmosphere above the escape velocity (Zahnle et al. 2006), and thus the primary atmosphere as a whole would be lost over the course of hours. Before it was lost the primary atmosphere may have influenced the redox state of the planetesimals directly, or indirectly by being a source of reduced solids that subsequently were folded into the planet. For example, nitrogenous organics or highly reduced nitrides may have been synthesized in the primary atmosphere and precipitated as solids to the surface, and thus remained behind when the atmosphere escaped.

\section{Secondary Atmospheres}

The disparity between the abundances of the noble gases and other volatile elements was first realized 85 years ago by F. W. Aston, who received the Nobel Prize in Chemistry for his pioneering work in mass spectroscopy. Aston (1924) concluded that the noble gases are abnormally scarce on the Earth in comparison to other elements. Aston also argued that the most plausible explanation for the rarity of the noble gases is that Earth is depleted in these elements. His conclusion was reinforced by Russell and Menzel (1933). They noted that astronomical spectra showed neon was abundant in the cosmos yet geochemists found it was scarce on Earth. This prior work and new data on the solar system abundances of the elements were incorporated into the secondary atmosphere model in the late 1940s by Brown (1949).

In the secondary model the atmosphere and oceans are produced by chemical reactions that released water and gases from condensed volatile-bearing materials during and/or after Earth's accretion. Brown showed that all volatile elements are depleted on Earth relative to their solar abundances. However, as noted earlier, the noble gases are much more depleted on Earth than the chemically reactive volatiles $(\mathrm{H}, \mathrm{C}, \mathrm{N}$, $\mathrm{O}$ gases). This is true even if one considers the probable noble gas inventories left in the undegassed portion of Earth's mantle and possible trapping of xenon in $\mathrm{Xe}$ clathrate hydrates $\mathrm{Xe} \cdot 6 \mathrm{H}_{2} \mathrm{O}$, which may be found as pure phases or a $\mathrm{Xe}-\mathrm{CH}_{4}$ clathrate hydrate solid solution $\left(\mathrm{CH}_{4}, \mathrm{Xe}\right) \cdot 6 \mathrm{H}_{2} \mathrm{O}$. The reason for this is simple-chemically reactive volatiles were incorporated into the solid grains accreted by the Earth during its formation but the noble gases were not.

The types of grains accreted by the Earth during its formation are exemplifed by chondritic meteorites (chondrites), which are primitive material from the solar nebula and are generally believed to be the building blocks of the Earth and other rocky asteroids, planets and satellites. Chondrites are undifferentiated (i.e., unmelted) stony meteorites containing metal+sulfide+silicate. The ordinary chondrites constitute about $97 \%$ of all chondrites. The rest of the chondrites fall mainly into two major groups, which are the carbonaceous and enstatite chondrites. Many geochemists think 
the Earth accreted from a mixture of chondritic materials (Wänke 1981; Lodders and Fegley 1997). Achondritic (i.e., melted and differentiated) material may also have been accreted by the Earth during its formation, but the volatile content of achondrites is generally much smaller than that of chondrites. This is possibly due to volatile loss from achondritic material during the heating that led to its melting and differentiation. Thus achondritic material probably made only minor contributions to the volatiles in Earth's early atmosphere and oceans.

\section{Volcanic Atmospheres}

The secondary origin of Earth's atmosphere led many to argue that the primordial atmosphere had the rather oxidized composition of volcanic gases (Poole 1951; Holland 1962; Abelson 1966). In modern volcanic gases the source is usually hot $(\sim 1500 \mathrm{~K})$ and only weakly reduced because the mantle is metal-free and the redox state is set by the QFM (Quartz-FayaliteMagnetite) buffer. The resulting atmosphere would be mostly $\mathrm{H}_{2} \mathrm{O}, \mathrm{CO}_{2}$, and $\mathrm{N}_{2}$, with small amounts of $\mathrm{CO}$ and $\mathrm{H}_{2}$ (Poole 1951; Holland 1962; Abelson 1966; Holland 1984). Geochemical proxies for the mantle redox state (e.g., the vanadium and chromium contents) in Earth's oldest igneous rocks indicate that the redox state of the Earth's mantle has not changed over the past 3.8 Gyr (Delano 2001; Canil 2002). It is understood that Earth's mantle cannot always have been metal-free, because Earth was made from matter in which rocky materials and metals were mixed, but $\mathrm{U}-\mathrm{Pb}$ and $\mathrm{Hf}-\mathrm{W}$ radiometric ages make clear that core formation in Earth was complete within a hundred million years of the origin of the solar system.

Urey (1951, 1952a, 1952b) argued instead that the secondary atmosphere of an accreting Earth would be cool and strongly reducing. He made the case that a reducing atmosphere would be better for the origin of life. Urey's model was inspired. He was the first to emphasize the importance of impact degassing and of the chemical reactions between the atmosphere and hot reduced impact ejecta (including iron rain), and he emphasized that the relatively oxidized state of modern volcanic gases is an evolutionary feature of Earth and not indicative of the primordial gases. But Urey left out two key processes: (1) He neglected the deep burial of impact energy, because he did not imagine collisions between planet-sized bodies-in Urey's model, Earth grew by accumulating asteroids. (2) He neglected the infrared thermal blanketing effect of the atmosphere; i.e., he ignored the greenhouse effect. His calculations explicitly assume blackbody cooling at the surface temperature. The result is that Earth accumulates as a cold body, an intimate mixture of metallic iron and silicates similar to that seen in ordinary chondrites, and that as a consequence the atmosphere is profoundly reducing.

\section{Impact Degassing}

Elemental analyses show that chondritic material is generally more volatile-rich than the Earth, but until recently the outgassing of volatiles from chondritic material during and/ or after accretion was a largely unexplored topic. In his unpublished masters thesis, Bukvic (1979) performed chemical equilibrium calculations for gas-solid equilibria in the upper layers of an Earth-like planet (suggested by his thesis advisor J. S. Lewis). He modeled the planet's composition using $\mathrm{H}$-chondritic or a mixture of $90 \% \mathrm{H}$-and $10 \% \mathrm{C}$-chondritic material. Bukvic used a volcanic outgassing scenario, assuming that the gas moved from depth to the surface without interacting or equilibrating with the intervening layers, to predict the composition of the initial atmosphere. He found that the major outgassing products were $\mathrm{N}_{2}$ at low temperatures and $\mathrm{CH}_{4}$ and $\mathrm{H}_{2}$ at higher temperatures. Bukvic never pursued this work further and it did not attract much attention for nearly 30 years, despite being discussed by Lewis and Prinn (1984).

Schaefer and Fegley (2007) reviewed the volatile contents of average ordinary chondrites. The data show that ordinary chondrites always contain substantial amounts of $\mathrm{C}$ and $\mathrm{H}$ : about $0.1 \% \mathrm{C}$ and $0.3 \% \mathrm{H}_{2} \mathrm{O}$ by weight. These fractions are both about ten times what is now present on Earth. It would be impossible to 
build a volatile-poor planet from these sorts of building blocks without granting a central role to volatile escape (Cameron 1983). Ordinary chondrites are volatile-poor compared to other primitive meteorites. The CI carbonaceous chondrites - which are admittedly volatilerich-have reduced carbon inventories of 3.5\% and water up to $10 \%$ by weight (Hashimoto et al. 2007). This means that a planetary atmosphere outgassed from materials like those in primitive meteorites would be substantial, with scope for thousands or tens of thousands of bars of steam and other gases.

The implication of the above is that Earth accreted as a volatile-rich body. Lange et al. (1985) and Tyburczy et al. (1986) addressed the experimental conditions under which water is degassed on impact. They found that this occurs from carbonaceous chondrites when impact velocities exceed $5 \mathrm{~km} / \mathrm{s}$. Thus, when planetesimals had become large enough (about the size of Mars) for impact velocities to routinely exceed $5 \mathrm{~km} / \mathrm{s}$, most of the volatiles in the impactors were delivered directly into the growing atmosphere. The first generation of impact degassing models emphasized water and steam (Abe and Matsui 1986; Matsui and Abe 1986a,b; Zahnle et al. 1988; Abe et al. 2000) because water vapor is an exceptionally potent greenhouse gas. These workers found that Earth's atmosphere, at least during the interval between the dissipation of the primary atmosphere and the Moon-forming impact, was for most of the time in a runaway greenhouse state and the surface would have been molten. The water was kept in the vapor state in part by sunlight but also in part by the energy released by Earth's accretion. Escape was undoubtedly important at the time, but it probably did not greatly influence the chemical composition of the atmosphere, given that Earth would also have been accreting vast amounts of metallic iron at the same time. Indeed the steam atmosphere was likely to have been strongly or mildly reduced.

Three recent studies address the chemical composition of the impact-degassed steam atmosphere. Ordinary chondrites are usually regarded as a useful albeit imperfect guide to what Earth was made of (Drake and Righter 2002). Schaefer and Fegley (2007) used chemical equilibrium calculations to model gas-solid equilibria during outgassing of ordinary $(\mathrm{H}, \mathrm{L}$, LL) chondritic material over wide pressure and temperature ranges. They are strongly reducing because they contain metallic iron and iron sulfides. The three major types of ordinary chondrites - H, L, and LL - reflect high, low, and very low metal abundances. Schaefer and Fegley's results turn out to be not very sensitive to type.

Because conventional wisdom said otherwise, Schaefer and Fegley were surprised to find that $\mathrm{CH}_{4}, \mathrm{H}_{2}, \mathrm{H}_{2} \mathrm{O}, \mathrm{N}_{2}$, and $\mathrm{NH}_{3}$ are the major gases produced by heating ordinary chondritic material up to the solidus temperature $(\sim 1225 \mathrm{~K})$ where $\mathrm{Fe}-\mathrm{Ni}$ sulfide begins to melt. Thus, their results confirmed those obtained by Bukvic (1979) for outgassing of ordinary $(\mathrm{H})$ chondritic material. Furthermore, Schaefer and Fegley (2007) found that their conclusions were remarkably insensitive to variations in the assumed temperature, total pressure and volatile element abundances over wide ranges. Carbon monoxide replaces $\mathrm{CH}_{4}$ as the major carbon gas at higher temperatures, with the exact temperature depending on the total pressure. For example, 1:1 ratios of $\mathrm{CO}$ to $\mathrm{CH}_{4}$ occur at $\sim 1000 \mathrm{~K}$ at one bar total pressure and $\sim 1200 \mathrm{~K}$ at 100 bar total pressure. To first approximation their model is dominated by the quartz-fayalite-iron (QFI) buffer, which is significantly more reduced than the better known iron-wustite (IW) buffer. Experimental work confrms their result. Although the focus of their study was asteroid-sized bodies, the prominence of methane in particular led them to extend the work to Earth. They concluded that Earth's early atmosphere contained $\mathrm{CH}_{4}$, $\mathrm{H}_{2}, \mathrm{H}_{2} \mathrm{O}, \mathrm{N}_{2}$, and $\mathrm{NH}_{3}$, similar to the gas mixtures used in the Miller-Urey synthesis of organic compounds. Illustrative results from calculations of this type are shown in Figure 1.

Hashimoto et al. (2007) also addressed the composition of gases generated in equilibrium with the projectile in the context of an impact degassed primordial atmosphere, and they too concluded that primordial methane-ammonia 
Hadean Atmosphere

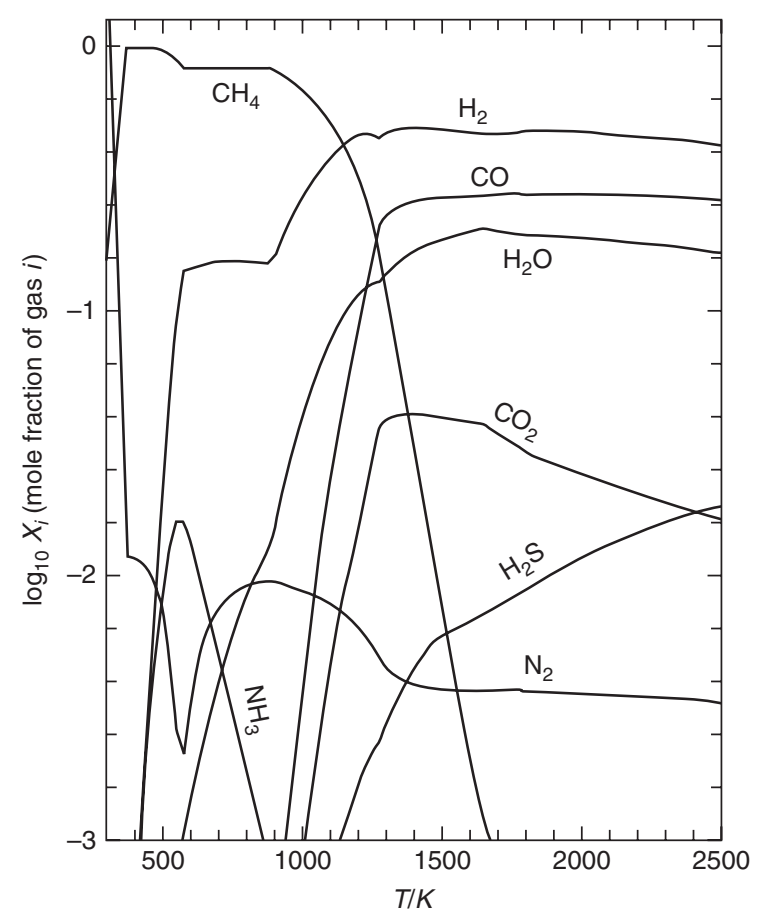

Figure 1. Gas compositions in equilibrium with ordinary H-type (high iron) chondrites at 100 bars (Schaefer and Fegley 2010). Abundances and oxygen fugacities are consistent with what is measured in ordinary H-type chondrites. Ordinary chondrites are often regarded as indicative of the bulk material of the Earth, although in detail the match is imperfect (Drake and Righter 2002). The gases are very reduced and at 100 bars pressure methane is strongly favored. The disappearance of $\mathrm{CH}_{4}$ at very low temperatures indicates that graphite has become the stable form of carbon. The temperature axis can also be interpreted as quench temperatures in the cooling impact ejecta plume or after some other cause of flash heating, for example by lightning or by impact. Generally similar results are obtained for other ordinary chondrites and enstatite chondrites (both EL and EH), because all contain significant amounts of metallic iron and iron sulfides (Schaefer and Fegley 2010).

atmospheres were plausible. In their model, gas compositions at 1 and 100 bar fixed pressures are computed as a function of temperature assuming volatile abundances and oxygen fugacities appropriate to CI carbonaceous chondritic materials. CI chondrites do not contain metallic iron, but they do contain a lot of reduced carbon, which is the source of their reducing power. These are the most highly oxidized meteorites and should generate the mostly highly oxidized gases that could be derived from a meteoritic source. Their results are indeed more oxidized than the gases from ordinary chondrites, but they are still notably reduced so that both $\mathrm{CH}_{4}$ and $\mathrm{NH}_{3}$ are produced. However, Hashimoto et al. do not show $\mathrm{H}_{2} \mathrm{O}$, which makes it impossible to determine what the gas composition actually is, because the major gas is usually water vapor. Figure 2, adapted from Schaefer and Fegley (2010), provides a clearer picture of the scenario addressed by Hashimoto et al.

Schaefer and Fegley (2010) extended their earlier work to consider a wider range of meteorite types, including carbonaceous and enstatite chondrites and mixtures of carbonaceous, ordinary, and enstatite chondritic material, which span the range of plausible planetary materials. Schaefer and Fegley again used chemical equilibrium calculations over a wide pressure and temperature range. They also considered the chemical kinetics of key reactions involved in the formation of $\mathrm{CH}_{4}$. Schaefer and Fegley (2010) found that $\mathrm{CO}_{2}$ is generally 
K. Zahnle, L. Schaefer, and B. Fegley

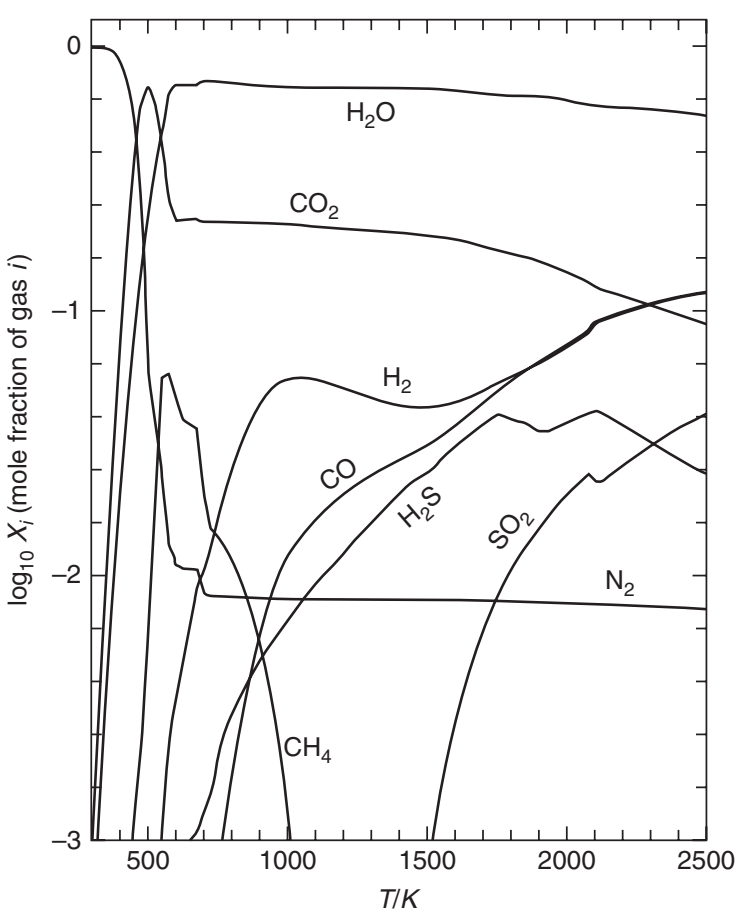

Figure 2. Gas compositions in equilibrium with CI chondrites at 100 bars (Schaefer and Fegley 2010). Abundances and oxygen fugacities are consistent with what is measured in carbonaceous chondrites. Carbonaceous chondrites are the most highly oxidized meteorites, and thus the gases that result are relatively highly oxidized; the chief source of reducing power is the reduced carbon itself. The temperature axis can also be interpreted as quench temperatures. Hashimoto et al. (2007) obtained generally similar results for similar assumptions.

the major carbon-containing gas produced by heating $\mathrm{CI}$ and $\mathrm{CM}$ carbonaceous material. In contrast, $\mathrm{CI}$ and $\mathrm{CM}$ carbonaceous material does not produce $\mathrm{CH}_{4}$ in any appreciable amounts on heating. Carbon monoxide or $\mathrm{CH}_{4}$ are the major carbon gases released by outgassing CV carbonaceous material, whereas methane (at low temperatures) or CO (at high temperatures) are the major carbon gases released by heating enstatite chondritic material. The line along which $\mathrm{CH}_{4}$ and $\mathrm{CO}$ have 1:1 ratios is very similar to that for ordinary chondritic material. Finally, Schaefer and Fegley (2010) found that mixtures of chondritic material also give $\mathrm{CH}_{4}$ or $\mathrm{CO}$-bearing gases unless $\mathrm{CI}$ or $\mathrm{CM}$ carbonaceous chondritic material makes up most of the mixture. Figures 2 and 1 are modified from this work.

To a first approximation the three new studies reach essentially the same conclusion from the same premise: If the gases of Earth's earliest atmosphere had equilibrated with material like that in primitive meteorites, the atmosphere that results would be much more reduced than modern volcanic gases. These results apply to impact-degassing both before and after the Moon-forming impact.

\section{RECENT RESULTS}

\section{The Moon-forming Impact}

It is now widely accepted that the Moon formed by the collision of two planets, one roughly the size of Mars and the other roughly the size of Earth (Benz et al. 1986; Cameron and Benz 1991; Canup and Asphaug 2001; Canup 2004). The collision took place $30-100 \mathrm{Myr}$ after the formation of the Solar system-there is some disagreement over how the key Hf-W 
and $\mathrm{U}-\mathrm{Pb}$ chronometers are to be interpreted. The impact was a major punctuating event in Earth's history. Zahnle et al. 2007 recently developed a speculative narrative history of the Hadean Earth beginning with the Moonforming impact and ending with the rock record in the Archean. Figure 3 reduces the story to a single picture in four stages.

The first stage is a hot silicate vapor atmosphere that would have cooled and condensed over $\sim 1000$ years. As the gas cooled the silicates would have rained out according to a condensation sequence, with the relatively volatile rockforming elements such as $\mathrm{Na}$ remaining in the atmosphere for a relatively long time. At first the metallic iron from the core of the impacting body will not have fully migrated to the core, as some of the iron will have been emulsified by its high speed interaction with Earth's mantle, which suggests that the rock vapor might have been rather reduced. In hot rock vapor two of the most abundant gases are $\mathrm{SiO}$ and $\mathrm{O}_{2}$, and as the vapor cools several geochemical volatiles_-sodium in particular-remain abundant in the gas phase (Schaefer and Fegley 2009). It is reasonable to expect that the most volatile elements would have partitioned between the atmosphere and the mantle according to their solubility in silicate melt, with much of the $\mathrm{H}_{2} \mathrm{O}$ and perhaps the sulfur entering the mantle, whereas $\mathrm{CO}, \mathrm{CO}_{2}$ and most other gases likely going into the atmosphere. Whether the

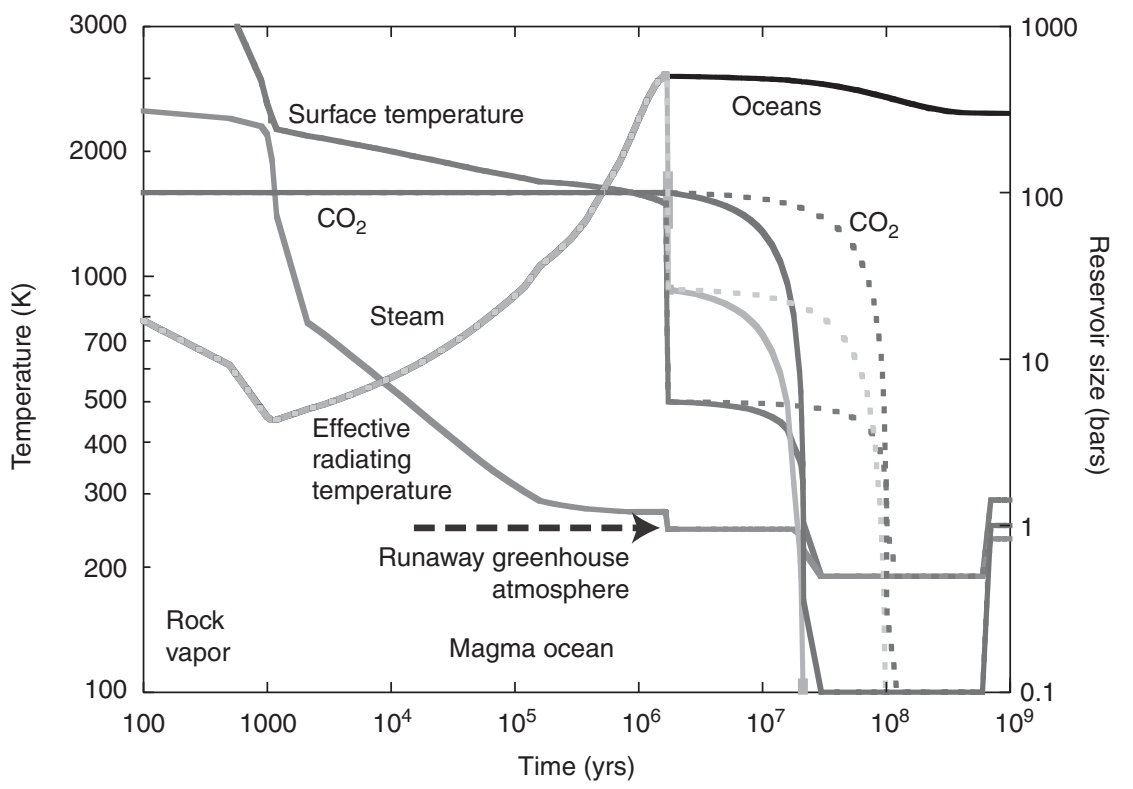

Figure 3. A schematic but energetically self-consistent history of temperature, water, and $\mathrm{CO}_{2}$ during the Hadean (after Zahnle et al. 2006). Steam and $\mathrm{CO}_{2}$ are in bars and read off the right hand axis; the pressure equivalent of the modern ocean is 270 bars. The Hadean began with a bang. (i) For 100-1000 yr after the Moon-forming impact Earth was enveloped in rock vapor. (ii) This was followed by a deep magma ocean that lasted for some 2 million years. The cooling rate was controlled by the thermal blanketing effect of water vapor and other greenhouse gases. (iii) Once the mantle solidified the steam in the atmosphere condensed to form a warm $(\sim 500 \mathrm{~K})$ liquid water ocean under $\sim 100$ bars of $\mathrm{CO}_{2}$. This particular model assumes that $\mathrm{CO}_{2}$ was the major atmospheric gas apart from water. The warm early Earth would have lasted while Earth's $\mathrm{CO}_{2}$ remained in the atmosphere. Here we assume that $\mathrm{CO}_{2}$ reacts with the seafloor and is subducted into the mantle on either a $20 \mathrm{Myr}$ (solid curves) or a $100 \mathrm{Myr}$ (dotted curves) time scale. (iv) The combination of the high chemical reactivity of ultramafc impact ejecta with $\mathrm{CO}_{2}$ and the faint early Sun suggests that, in the absence of another abundant greenhouse gas, the Earth should have become ice covered and very cold (Koster van Groos 1988; Sleep and Zahnle 2001). Occasional big impacts would have brought brief thaws (not shown). 
atmosphere is reduced (mostly $\mathrm{H}_{2}$ and $\mathrm{CO}$, as in Fig. 1) or oxidized (mostly $\mathrm{H}_{2} \mathrm{O}$ or $\mathrm{CO}_{2}$, as in Fig. 2) probably depends on how quickly the stranded metallic iron from the impactor regathers itself into drops and rains to the core. With the metals gone, the mantle is likely to support a relatively oxidized atmosphere dominated by $\mathrm{H}_{2} \mathrm{O}$ and $\mathrm{CO}_{2}$.

Genda and Abe $(2003,2005)$ showed that Earth is unlikely to lose much of its water as a result of the Moon-forming impact, although loss of a significant amount of atmosphere is possible. Hence Earth's cooling after the silicates had rained out would have been controlled by the steam in the atmosphere, with the asymptotic cooling rate set by the $\sim 300 \mathrm{~K}$ radiating temperature of a water vapor runaway greenhouse. Because the liquid mantle convects easily, it cools as soon as the atmosphere permits. During this time the geothermal heat flow rivals sunlight in magnitude. It is probably also during this time that any iron from the intruder's core that was stranded in the mantle descended as a molten rain to the core and the mantle became metal-free. The mantle would have frozen from the bottom up, because the melting point of silicates is a strong function of pressure. With the cooling rate controlled by the atmosphere it takes $\sim 2$ Myrs for magma ocean to freeze to the surface.

Most of the water that had been dissolved in the mantle degassed as the volume of magma shrank. Two million years is not enough time for selective hydrogen escape to oxidize the planet significantly, so the relevant buffer is likely to have remained reduced. Although the radiating temperature is cool the surface temperature is $>1500 \mathrm{~K}$. Kinetic inhibitions against forming $\mathrm{CH}_{4}$ and $\mathrm{NH}_{3}$ in the gas phase suggest that the gas composition was mostly $\mathrm{H}_{2}, \mathrm{CO}$, $\mathrm{H}_{2} \mathrm{O}, \mathrm{CO}_{2}$, and $\mathrm{N}_{2}$, probably in this order.

Once the mantle has mostly solidified, the mantle no longer convects easily and the geothermal heat flow drops below the point where it can support a runaway greenhouse atmosphere. At this point the steam rains out to make hot salty oceans, salty because $\mathrm{NaCl}$ had been an abundant gas in the atmosphere. Other water soluble volatiles would also likely enter the ocean; these may have included various forms of sulfur compounds. Gases more volatile than $\mathrm{H}_{2} \mathrm{O}$ and only sparingly soluble in hot water would stay in the atmosphere. Based on the modest solubility of $\mathrm{CO}_{2}$ in magma we estimated that the atmosphere would have contained 100-200 bars of $\mathrm{CO}_{2}$ and the surface temperature would have been $\sim 500 \mathrm{~K}$. The preference for $\mathrm{CO}_{2}$ over $\mathrm{CO}$ or $\mathrm{CH}_{4}$ assumes a QFM-like (or CI- or CV-like) redox buffer. However, if a more reduced QFI-like buffer (EH-, EL-, or H-like) still applied, the $500 \mathrm{~K}$ atmosphere would be mostly methane with very little $\mathrm{CO}$ or $\mathrm{CO}_{2}$. This seems unlikely, because the ocean and atmosphere were in close contact with a balsaltic seafloor crust that is not very reducing.

The fourth stage begins when $\mathrm{CO}_{2}$ is removed from the atmosphere. As Urey (1952b) pointed out, a thick primordial $\mathrm{CO}_{2}$ atmosphere, a liquid water ocean, and a basalt crust do not make a stable tripod. The $\mathrm{CO}_{2}$ will react to make carbonates and thus be removed from the atmosphere (Sleep et al. 2001). Vigorous hydrothermal circulation through the oceanic crust and rapid mantle turnover could have moved 100 bars of $\mathrm{CO}_{2}$ from the atmosphere into the mantle in less than 10 million years (Sleep 2010). However, the rest of the $\mathrm{CO}_{2}$ cycle remains obscure, which makes it difficult to predict how quickly this would have happened or what the asymptotic atmospheric $\mathrm{CO}_{2}$ level would have been (Sleep et al. 2001).

\section{After the Moon-forming Impact}

Without potent greenhouse gases, the surface of the Hadean Earth might have been extremely cold because the young Sun was faint. This would be the case if most of Earth's $\mathrm{CO}_{2}$ had reacted with rock to form carbonates (Sleep and Zahnle 2001). The surface temperature could then drop as low as $\sim 220 \mathrm{~K}$ and the oceans would be ice-covered, somewhat resembling the oceans of Europa. But unlike Europa, Earth's atmosphere was thick and the heat flow would have been high enough to ensure that the ice cover would have been thin $(<100 \mathrm{~m})$ in many places. Such thin ice would break 
and form leads. Emergent active volcanoes would each have skirts of liquid water. Volcanic $\mathrm{CO}_{2}$ would only build up to a point, because it would enter the ocean through the holes in the ice. This describes a negative feedback, in which $\mathrm{CO}_{2}$ is regulated so that its greenhouse effect is just big enough to ensure some open water.

Another factor affecting the climate is that hundreds or thousands of substantial asteroid impacts would have melted the ice, each impact triggering a brief impact summer. Iceball Earth is an interesting possibility that has at times been regarded as being favorable to the origin of life because freezing pools concentrate $\mathrm{HCN}$ and $\mathrm{H}_{2} \mathrm{CO}$, which combine in interesting ways (Bada et al. 1994). This path to the origin of life was featured by Leslie Orgel and Stanley Miller in Bronowski's The Ascent of Man (Bronowski 1973).

Several workers have shown that lightning (Chameides and Walker 1981) or bolide impacts (Fegley et al. 1986; Chyba and Sagan 1992) can produce modest amounts of HCN from strong shock heating in $\mathrm{CO}-\mathrm{N}_{2}-\mathrm{H}_{2} \mathrm{O}$ atmospheres. Yields are about three orders of magnitude larger in methane-ammonia atmospheres, and three orders smaller if the atmosphere is mostly $\mathrm{CO}_{2}$ rather than $\mathrm{CO}$. Somewhat surprisingly, given the null results obtained in similar experiments by Schlessinger and Miller (1983), Cleaves et al. (2008) report modest yields of ammonia, $\mathrm{HCN}$, and amino acids in spark discharge experiments in $\mathrm{CO}_{2}-$ $\mathrm{N}_{2}$-water systems, especially if they allow the $\mathrm{pH}$ of the water to become acidic. Recently Sugita and Schultz (2009) report that experiments simulating strong shocks in possible cometary materials destroy complicated organic matter but also generate $\mathrm{HCN}$.

Very large impacts can affect atmospheric chemistry in another way by wholly resetting the chemistry of the atmosphere, in manner akin to the Moon-forming impact but on a much smaller scale. South Pole-Aitken is the biggest impact crater on the Moon (it is on the far side). Orientale is representative of the great craters of the lunar late bombardment: there are about a dozen of these on the
Earth-facing side of the Moon; others include Crisium, Serenitatis, Nectaris, and Imbrium. Earth would have experienced hundreds of comparable impacts ca. 3.9 Ga during the late lunar bombardment. Figures 4 and 5 illustrate the effects of South Pole-Aitken and Orientalescale impacts on the Earth.

Solar ultraviolet light (UV) is another source of disequilibrium chemistry. For the Miller-Urey methane-ammonia atmosphere UV is both good and bad: it drives the chemistry that makes interesting molecules, but that chemistry can also destroy methane and ammonia. These two consequences are inseparable.

It is sometimes suggested that high altitude organic hazes can have a shielding effect that protects the methane and ammonia from rapid destruction by UV (Sagan and Chyba 1997). Titan's atmosphere is often regarded as chemically analogous to early Earth but the comparison is strained because its atmosphere is too cold for oxygen (the element) to have a significant role. But Titan is enough of an analog to suggest that such hazes will be ineffective. Titan's organic hazes are produced by UV and solar wind irradiation of $\mathrm{CH}_{4}$ and $\mathrm{N}_{2}$. The rate that $\mathrm{CH}_{4}$ is destroyed is equal to the rate at which hydrogen escapes to space. The hydrogen escape rate was measured by the Cassini spacecraft, which few through the expanding cloud of hydrogen, and was found to be comparable to the incident UV photon flux (Cui et al. 2008). The conclusion is that the organic haze offers very little protection against the destructive or constructive effects of incident radiation.

Pinto et al. (1980) and Wen et al. (1989) showed theoretically that formaldehyde can be produced photochemically in small amounts in $\mathrm{CO}_{2}$-dominated atmospheres. Bar-Nun and Chang (1983) obtained small amounts of interesting organic matter by irradiating $\mathrm{CO}-\mathrm{H}_{2} \mathrm{O}$ mixtures at $185 \mathrm{~nm}$. Zahnle (1986) showed that HCN can be produced in high yields photochemically from EUV photolysis of $\mathrm{N}_{2}$ in $\mathrm{CO}_{2}-\mathrm{N}_{2}$ atmospheres provided that methane is present in significant amounts. The process exploits the high EUV radiation emitted by the young active Sun (the young Sun was only $70 \%$ as bright as it is now, but it was a much 
K. Zahnle, L. Schaefer, and B. Fegley
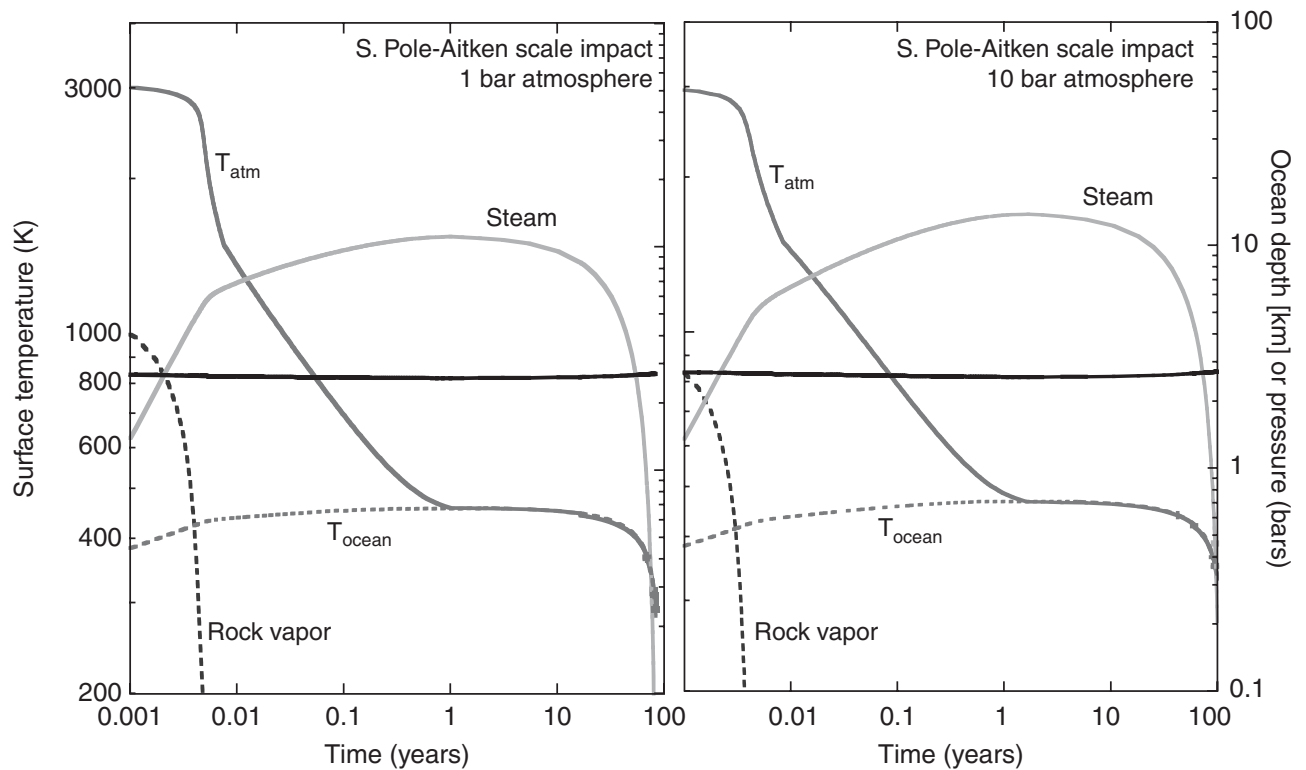

Figure 4. Thermal response of Earth to an impact on the scale of the impact that created the lunar S. Pole-Aitken basin. Tens of these occurred on Earth during the Hadean. The total energy released is $10^{34}$ ergs; we assume that half promptly escapes to space or is deeply buried. The calculations assume an ocean of water (or ice) and either 1 or 10 bars of preexisting atmosphere. The method of calculation is described in Nisbet et al. (2006). The plot shows the temperatures of the atmosphere and ocean, the effect of evaporation on the depth of the ocean, and the pressures of steam and rock vapor. These atmospheres are thin enough to be heated to the temperature of rock vapor, which resets the chemical state of the entire atmosphere. The atmosphere will likely equilibrate with the rock vapor, which in many cases will be dominated by materials from the impacting body. An upper limit on the consequences for an ordinary chondritic impactor can be inferred from Figure 1. If the effective quench temperature is $\sim 1500 \mathrm{~K}$, the result would be a CO-rich atmosphere. If the effective quench temperature were as low as $\sim 1000 \mathrm{~K}$, the result would be methane. In practice these are upper limits because the atmosphere itself before the impact will have been more oxidized (either by hydrogen escape or by interaction with the mantle), and these pre-ëxisting oxidants would need to be accounted for.

larger source of nonthermal radiation, including vacuum UV and X-rays, by factors of $10-100)$. Such an atmosphere would require a significant methane source. One possibility is low temperature equilibria pertinent to hydrothermal circulation through new seafoor, another would be impact degassing of chondritic impactors as discussed in detail earlier.

\section{CHALLENGES AND FUTURE RESEARCH DIRECTIONS}

Delivering all Earth's volatiles after the Moonforming impact is quantitatively challenging. Extreme siderophile elements-elements such as osmium and iridium that are strongly concentrated in the metallic core-are found in Earth's mantle in the relative proportions that they are found in chondritic meteorites, but at much smaller concentrations. The extreme siderophiles imply that Earth accreted the equivalent of a $20 \mathrm{~km}$ thick blanket of chondritic materials after iron had stopped migrating to the core (Anders 1989). Some of this may represent material from the core of the Moon-forming impactor. In either case, osmium isotopes show that this material resembled ordinary chondrites rather than the more volatile-rich carbonaceous chondrites (Meisel et al. 2001; Drake and Righter 2002). The total volatile load delivered by $20 \mathrm{~km}$ of ordinary chondrites that are $0.3 \%$ water by 

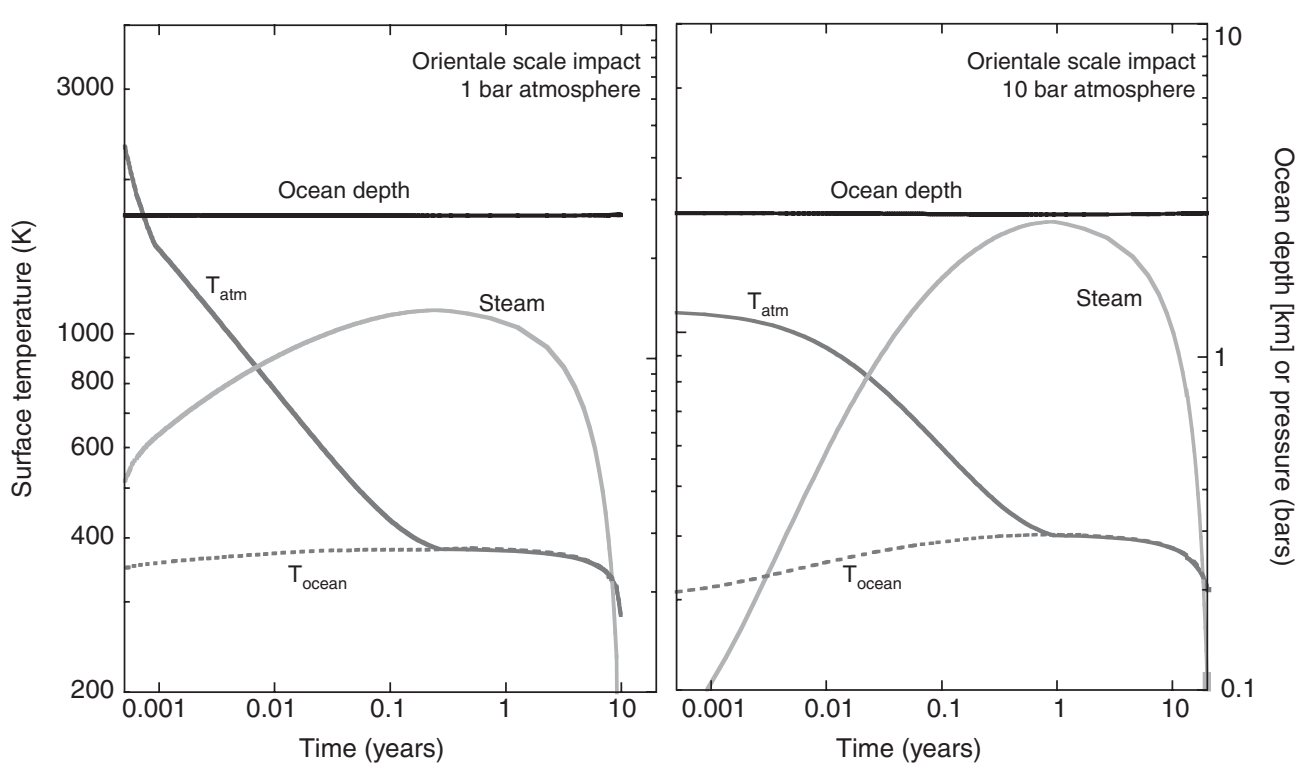

Figure 5. Thermal response of Earth to an impact on the scale of the impact that created the lunar Orientale basin. Hundreds of these occurred on Earth during the Hadean. The total energy is $10^{33}$ ergs. The plot shows the temperatures of the atmosphere and ocean, the effect of evaporation on the depth of the ocean, and the steam pressure. The 1 bar atmosphere is thin enough that rock vapor should briefly raise the temperature of the atmosphere to $\sim 2500 \mathrm{~K}$, but the event is brief and the system may not time enough to equilibrate thermally or chemically before the rock vapor precipitates. The 10-bar atmosphere is thick enough to effectively quench the impact, and a higher fraction of the impact's energy goes into evaporating rather than into thermal radiation to space. The chemical consequences of such impacts might be considerable, especially in the latter case where methane would seem strongly favored.

weight (Schaefer and Fegley 2007) is equivalent to the delivery of only $200 \mathrm{~m}$ of water, well short of an ocean. Only the wettest vectors, e.g., comets, could deliver an ocean of water in such a small total mass.

Application of Schaefer and Fegley (2007, 2010) and Hashimoto et al. (2007) scenarios to the late volatile hypothesis is straightforward. Earth is fully formed and impact velocities are high. Hence impacts are extremely energetic and to first approximation we can expect all the volatiles (and many of the refractory elements as well) carried by the impactors to be vaporized by impact, to equilibrate chemically with the other materials of the impactor, and to enter the atmosphere. This situation was addressed by Hashimoto et al. (2007) and Schaefer and Fegley (2010) using carbonaceous chondrites as the starting material. Both find that the gases that result are rather strongly reducing despite the minerals being rather oxidized. This occurs because these meteorites are carbon rich, and the bulk of the carbon is present in reduced form (Fig. 2). Thus the impacts of the late bombardment represent a substantial stochastic source of reduced gases to the atmosphere.

Kasting (1990) used an atmospheric photochemical model with redox tracking to show that meteoritic material falling on young Earth can produce a CO-rich atmosphere. In these models the atmospheric chemistry is computed assuming a steady state redox balance between reduced sources (volcanic gases and exogenic input of reduced matter, principally meteoritic iron and iron sulfides) and hydrogen escape. The latter is presumed to take place at the physical upper limit imposed by diffusion of hydrogen through the background gases. The presumption is that escape is easy once the 
hydrogen reaches the thermosphere. Kasting did not predict the synthesis of $\mathrm{CH}_{4}$ or $\mathrm{NH}_{3}$ because he knew no effective photochemical pathways for converting $\mathrm{CO}$ to $\mathrm{CH}_{4}$ or $\mathrm{N}_{2}$ to $\mathrm{NH}_{3}$, and he assumed the geologist's $\mathrm{CO}_{2}-\mathrm{N}_{2}-$ $\mathrm{H}_{2} \mathrm{O}$ atmosphere as a base state. Kasting found that the incoming flux of meteoritic iron could be big enough to flip the redox state of the atmosphere from $\mathrm{CO}_{2} \gg \mathrm{CO}$ to $\mathrm{CO} \gg$ $\mathrm{CO}_{2}$, although to do so the mean impact flux had to be comparable to the upper bound inferred from the lunar impact record. On the other hand, Kasting treated the input of meteoritic iron as a continuous function, which is not a good approximation for a distribution of impacts, which tend to be dominated by the few largest objects. This means that the delivery of new iron and iron sulfide would be stochastic, with very large excursions from the mean. If the transient effect of impacts is considered, it seems very likely that each major impact would convert a photochemically sensitive atmosphere from $\mathrm{CO}_{2}$ to $\mathrm{CO}$. It has also been suggested that iron grains can catalyze the conversion of $\mathrm{CO}$ to $\mathrm{CH}_{4}$ (Kress and McKay 2004). The central role of iron in an impact-driven atmospheric chemistry was anticipated by Urey (1952b).

A recent model suggesting that hydrogen escape may not have been as rapid as most photochemical calculations have taken it to be (Tian et al. 2005) is directly relevant to Kasting's model. If hydrogen escape were truly inefficient, the lifetime of transient reduced atmospheres would be greatly extended, and the balance between $\mathrm{CO}$ and $\mathrm{CO}_{2}$ would tip strongly in favor of the former. A consequence is that the atmosphere would be CO-dominated through most of the Hadean. Tian et al's argument that hydrogen escape was inefficient on early Earth assumes that the upper atmosphere would be cold as on Venus, because the atmosphere is composed mostly of $\mathrm{CO}_{2}$. Their claim is controversial because their model depends on gases other than hydrogen to provide the radiative cooling, but their model does not actually include gases other than hydrogen. In particular, the key assumption that the upper atmosphere was cold is not obvious and needs to be addressed quantitatively. Visconti (1975) computed the temperature of Earth's upper atmosphere if the lower atmosphere were anoxic. He obtained thermospheric temperatures well over $1000 \mathrm{~K}$ for current solar max EUV fluxes. EUV fluxes from the young Sun would have much bigger (Zahnle and Walker 1982), so that hotter thermospheres would be expected. Visconti's calculations contrast markedly with the cold thermospheres in Tian et al.'s pure hydrogen escape models.

Carbon monoxide is probably the easiest prebiotically interesting gas to generate in the post-Moon-forming-impact Hadean atmosphere. CO is relatively easy to generate abiotically in a wide range of plausible atmospheres, and it is packed with energy (with it organisms can eat water). CO could be formed by lightning, by impact shocks, or photochemically if there is a significant source of meteoritic of volcanic reducing power. The cold dry atmosphere of an iceball Earth is especially favorable to $\mathrm{CO}$ (Zahnle et al. 2008). The possible origin-of-life aspects of $\mathrm{CO}$ and its derivatives formamide (for pyrimidine synthesis, Powner et al. 2009) and OCS (condensing agent for forming peptide bonds, Leman et al. 2004) are catching attention, especially among prebiotic chemists who are attempting to synthesize an RNA world (Ricardo et al. 2004; Powner et al. 2009). There is also evidence that $\mathrm{CO}$ metabolism is very ancient (Ragsdale 2004). Modern methanogens first convert $\mathrm{CO}_{2}$ to $\mathrm{CO}$ with one enzyme ( $\mathrm{CO}$ dehydrogenase, or $\mathrm{CODH}$ ), and then apparently send the $\mathrm{CO}$ as a gas down a sealed tube to a second enzyme complex where it is used for energy or for cell material (Ragsdale 2004). This is known as the Wood-Ljundahl pathway of carbon assimilation; it can be regarded as parallel to the more famous Calvin cycle. The enzymes are both based on NiFeS cubes, fitting well with a separate speculation that the first metabolism made use of natural iron sulfides as catalysts (Wächtershäuser 1992).

\section{ACKNOWLEDGMENTS}

The authors would like to thank NASA's Exobiology and Astrobiology Program for support. 


\section{REFERENCES}

Abe Y. 1993. Physical state of very early Earth. Lithos 30: 223-235

Abe Y. 1997. Thermal and chemical evolution of the terrestrial magma ocean. Phys Earth Planet Int 100: 27-39.

Abe Y, Matsui T. 1986. Early Evolution of the Earth: Accretion, Atmosphere Formation, and Thermal History. J Geophys Res 91: E291-E302.

Abe Y, Ohtani E, Okuchi T, Righter K, Drake M. 2000. Water in the Early Earth. In Origin of the Earth and Moon. R.M. Canup, K. Righter (eds.), University of Arizona Press, pp. $413-433$.

Abelson PH. 1966. Chemical Events on the Primitive Earth. Proc Nat Acad Sci 55: 1365-1372.

Ahrens TJ, O'Keefe JD, Lange MA. 1989. Formation of atmospheres during accretion of the terrestrial planets. In Origin and Evolution of Planetary and Satellite Atmospheres. S.K. Atreya, J.B. Pollack, M.S. Matthews (eds.), University of Arizona Press, pp. 328-385.

Albarède F. 2009. Volatile accretion history of the terrestrial planets and dynamic implications. Nature. 461: 12271233.

Anders E. 1989. Pre-biotic organic matter from comets and asteroids. Nature 342: 255-257.

Arrhenius G, De BR, Alfvén H. 1974. Origin of the ocean. In The Sea, Vol. 5: E.D. Goldberg (Ed.) Wiley-Interscience, New York, pp. 839-861.

Aston FW. 1924. The rarity of the inert gases on Earth Nature 114: 786

Bada JL, Bigham C, Miller SL. 1994. Impact melting of frozen oceans on the early Earth: Implications for the origin of life. Proc Natl Acad Sci USA 91: 1248-1250.

Bar-Nun A, Chang S. 1983. Photochemical reactions of water and carbon monoxide in Earth's primitive atmosphere. J Geophys Res 88: 6662-6672.

Benz W, Slattery WL, Cameron AGW. 1986. The origin of the moon and the single-impact hypothesis. Icarus 66: 515-535.

Bronowski J. 1973. The Ascent of Man. Little Brown \& Co. 448 pp.

Brown H. 1949. Rare gases and the formation of the Earth's atmosphere. In The Atmosphere of the Earth and Planets. G. Kuiper (Ed.). Univ. Chicago Press, Chicago, pp. 258-266.

Cameron AGW. 1983. Origin of the atmospheres of the terrestrial planets. Icarus 56: 195-201.

Cameron AGW, Benz W. 1991. The origin of the moon and the single impact hypothesis. Icarus 92: 204-216.

Canil D. 2002. Vanadium in peridotites, mantle redox and tectonic environments: Archean to present. Earth Planetary Science Letters 195: 75-90.

Canup RM. 2004. Simulations of a late lunar-forming impact. Icarus 168: 433-456.

Canup RM, Asphaug E. 2001. Origin of the Moon and the single impact hypothesis. Nature 421: 708-712.

Chameides WL, Walker JCG. 1981. Rates of fxation by lightning of carbon and nitrogen in possible primitive atmospheres. Origins of Life 11: 291-302.
Chyba CF, Sagan C. 1992. Endogenous production, exogenous delivery and impact-shock synthesis of organic molecules: An inventory for the origins of life. Nature 355: $125-132$.

Chyba CF, Thomas PJ, Brookshaw L, Sagan C. 1990. Cometary Delivery of Organic Molecules to the Early Earth. Science 249: 366-373.

Clark BC. 1988. Primeval procreative comet pond. Orig Life Evol Biosph 18: 209-238.

Clark PD, Dowling NI, Huang M. 1998. Comments on the role of $\mathrm{H}_{2} \mathrm{~S}$ in the chemistry of Earth's early atmosphere and in prebiotic synthesis. J Mol Evol 47: 127-32.

Cleaves HJ, Chalmers JH, Lazcano A, Miller SL, Bada JL. 2008. A reassessment of prebiotic organic synthesis in neutral planetary atmospheres. Orig Life Evol Biosph 38: $105-1156$.

Cui J, Yelle RV, Volk K. 2008. Distribution and escape of molecular hydrogen in Titan's thermosphere and exosphere. J Geophys Res 113: E10004.

Delano JW. 2001. Redox history of the Earth's interior since approximately $3900 \mathrm{Ma}$ : Implications for prebiotic molecules. Orig Life Evol Biosph 31: 311-341.

Drake M, Righter K. 2002. Determining the composition of the Earth. Nature 416: 39-44.

Fegley B, Prinn RG, Hartman H, Watkins GH. 1986. Chemical effects of large impacts on the Earth's primitive atmosphere. Nature 319: 305-308.

Ferris JF, Joshi PC, Edelson EH, Lawless JG. 1978. HCN: A plausible source of purines, pyrimidines and amino acids on the primitive Earth. J Mol Evol 11: 293-311

Frei R, Gaucher C, Poulton SW, Canfeld DE. 2009. Fluctuations in Precambrian atmospheric oxygenation recorded by chromium isotopes. Nature 461: 250-253.

French BM. 1966. Some Geological Implications of Equilibrium between Graphite and a C-H-O Gas Phase at High Temperatures and Pressures. Rev Geophys Space Phys 4: 223-253.

Genda H, Abe Y. 2003. Survival of a proto-atmosphere through the stage of giant impacts: The mechanical aspects. Icarus 164: 149-162.

Genda H, Abe Y. 2005. Enhanced atmospheric loss on protoplanets at the giant impact phase in the presence of oceans. Nature 433: 842-844.

Harrington J, de Pater I, Brecht SH, Deming D, Meadows V, Zahnle K, Nicholson P. 2004. Lessons from ShoemakerLevy 9 about Jupiter and Planetary Impacts. In Jupiter: The Planet, Satellites and Magnetosphere. F. Bagenol, T. Dowling, W. McKinnon, Eds. Cambridge Univ. Press. pp $158-184$.

Hashimoto GL, Abe Y, Sugita S. 2007. The chemical composition of the early terrestrial atmosphere: Formation of a reducing atmosphere from CI-like material. J Geophys Res 112: $\mathrm{E} 05010$.

Hayashi C, Nakazawa K, Mizuno H. 1979. Earth's melting due to the blanketing effect of the primordial dense atmosphere. Earth Planet Sci Lett 43: 22-28.

Holland HD. 1962. Model for the evolution of the earths atmosphere. In Petrologic studies: a volume in honor of A.G. Buddington, E.J. Engle, H.L. James, B.F. Leonard (eds.). Geological Society of America, Boulder, pp 447-477. 
Holland HD. 1984. The Chemical Evolution of the Atmosphere and Oceans. Princeton University Press, Princeton, pp. 582.

Holland HD. 2002. Volcanic gases, black smokers, and the Great Oxidation Event. Geochimica et Cosmochimica Acta 66: 3811-3826.

Ikoma M, Genda H. 2006. Constraints on the Mass of a Habitable Planet with Water of Nebular Origin. Astrophys 648: $696-706$

Irvine WM. 1998. Extraterrestrial organic matter: A review. Orig Life Evol Biosph 28: 365-83.

Johnson AP, Cleaves HJ, Dworkin JP, Glavin DP, Lazcano A, Bada JL. 2008. The Miller Volcanic Spark Discharge Experiment. Science 322: 404.

Kasting JF. 1982. J Geophys Res 87: Pages 3091-3098.

Kasting JF. 1990. Bolide impacts and the oxidation state of carbon in the Earth's early atmosphere. Orig Life Evol Biosph 20: 199-231.

Kasting JF. 1991. $\mathrm{CO}_{2}$ Condensation and the Climate of Early Mars. Icarus 94: 1-13.

Kasting JF. 1993. Earth's early atmosphere. Science 259: 920-926.

Kasting JF, Catling D. 2003. Evolution of a habitable planet. Ann Rev Astron Astrophys 41: 429-463.

Koster van Groos AF. 1988. Weathering, the carbon cycle, and the differentiation of the continental crust and mantle. J Geophys Res 93: 8952-8958.

Kress ME, McKay CP. 2004. Formation of methane in comet impacts: Implications for Earth, Mars, and Titan. Icarus 168: $475-483$.

Kuhn WR, Atreya SK. 1979. Ammonia photolysis and the greenhouse effect in the primordial atmosphere of the earth. Icarus 37: 207-213.

Lange MA, Lambert P, Ahrens TJ. 1985. Shock effects on hydrous minerals and implications for carbonaceous meteorites. Geochim Cosmochim Acta 49: 1715-1726.

Lasaga AC, Holland HD, Dwyer MJ. 1971. Primordial Oil Slick. Science 174: 53-55.

Leman L, Orgel L, Ghadiri MR. 2004. Carbonyl Sulfide Mediated Prebiotic Formation of Peptides. Science 306: 283-286.

Lewis JS, Prinn RG. 1984. Planets and their atmospheresOrigin and evolution. Academic Press, Orlando, 480 pp.

Lodders K, Fegley B. 1997. An oxygen isotope model for the composition of Mars. Icarus 126: 373-394.

Matsui T, Abe Y. 1986a. Impact-induced atmospheres and oceans on earth and Venus. Nature 322: 526-528.

Matsui T, Abe Y. 1986b. Evolution of an impact-induced atmosphere and magma ocean on the accreting earth. Nature. 319: 303-305.

Maurette M. 1998. Carbonaceous micrometeorites and the origin of life. Orig Life Evol Biosph 28: 385-412.

Meisel T, Walker RJ, Irving AJ, Lorand J-P. 2001. Osmium isotopic compositions of mantle xenoliths: A global perspective. Geochim Cosmochim Acta 65: 1311-1323.

Miller SL. 1953. A Production of Amino Acids under Possible Primitive Earth Conditions. Science 117: 528-529.

Miller SL. 1955. Production of some organic compounds under possible primitive Earth conditions. J Am Chem Soc 77: 2351-2361.
Miller SL. 1986. Current status of the prebiotic synthesis of small molecules. Chem Scr 26B: 5-11.

Miller SL, Bada JL. 1988. Submarine hot springs and the origin of life. Nature 334: 609-611.

Miller SL, Bada JL. 1993. Comment on "Summary and implications of reported amino acid concentrations in the Murchison meteorite" by EL Shock and MD Schulte. Geochim Cosmochim Acta 57: 3473-3474.

Miller SL, Urey HC. 1959. Organic compound synthesis on the primitive Earth. Science 130: 245-251.

Nisbet EG, Zahnle KJ, Gerasimov MV, Helbert J, Jaumann R, Hofmann BA, Benzerara K, Westall F. 2006. Creating habitable zones, at all scales, from planets to mud microhabitats, on Earth and on Mars. Space Sci Rev 129: 79-121.

Oró J, Kamat S. 1961. Amino-acid synthesis from hydrogen cyanide under possible primitive Earth conditions. Nature 190: 442-443.

Oró J, Miller SL, Lazcano A. 1990. The origin and early evolution of life on Earth. Ann Rev Earth Planet Sci 18: 317-56.

Pasek M, Lauretta D. 2008. Extraterrestrial fux of potentially prebiotic C, N, and P to the early Earth. Orig Life Evol Biosph 38: 5-21.

Pierazzo E, Chyba CF. 1999. Amino acid survival in large cometary impacts. Meteoritics Planet Sci 34: 909-918.

Pinto JP, Gladstone GR, Yung YL. 1980. Photochemical Production of Formaldehyde in Earth's Primitive Atmosphere. Science 210: 183-185

Poole JHJ. 1951. The evolution of the earth's atmosphere. Sci Proc Roy Dublin Acad 25: 201-224.

Powner MW, Gerland B, John D, Sutherland JD. 2009. Synthesis of activated pyrimidine ribonucleotides in prebiotically plausible conditions. Nature 459: 239-242.

Ragsdale SW. 2004. Life with carbon monoxide. Crit Rev Biochem Mol Biol 39: 165-195.

Ricardo A, Carrigan MA, Olcott AN, Benner SA. 2004. Borate Minerals Stabilize Ribose. Science 303: 196.

Russell HN, Menzel DH. 1933. The Terrestrial Abundance of the Permanent Gases. Proc Nat Acad Sci 19: 997-1001.

Sagan C, Chyba CF. 1997. The early faint sun paradox: Organic shielding of ultraviolet-labile greenhouse gases. Science 276: 1217-1221.

Schaefer L, Fegley B. 2007. Outgassing of ordinary chondritic material and some of its implications for the chemistry of asteroids, planets, and satellites. Icarus 186: 462483 .

Schaefer L, Fegley B. 2009. Chemistry of Silicate Atmospheres of Evaporating Super-Earths Submitted to Astrophys. J Lett [in press].

Schaefer L, Fegley B. 2010. Chemistry of Atmospheres Formed during Accretion of the Earth and Other Terrestrial Planets, Submitted to Icarus 17 Sept. 2009.

Schlesinger G, Miller SL. 1983. Prebiotic synthesis in atmospheres containing $\mathrm{CH}_{4}, \mathrm{CO}$ and $\mathrm{CO}_{2}$. I Amino acids $\mathrm{J} \mathrm{Mol}$ Evol 19: 376-382.

Sekiya M, Hayashi C, Kanazawa K. 1981. Dissipation of the primordial terrestrial atmosphere due to irradiation of the solar far-UV during T tauri stage. Prog Theor Phys 66: $1301-1316$. 
Sekiya M, Nakazawa K, Hayashi C. 1980. Dissipation of the primordial terrestrial atmosphere due to irradiation of the solar EUV. Prog Theor Phys 64: 1968-1985.

Shock EL. 1990. Geochemical constraints on the origin of organic compounds in hydrothermal systems. Orig Life Evol Biosph 20: 331-367.

Shock EL, McCollom T, Schulte M. 1995. Geochemical constraints onbchemolithoautotrophic reactions in hydrothermal systems. Orig Life Evol Biosph 25: 141-159.

Shock EL, McKinnon WB. 1993. Hydrothermal processing of cometary volatiles-Applications to Triton. Icarus 106: $464-477$.

Shock EL, Schulte MD. 1990. Amino-acid synthesis in carbonaceous meteorites by aqueous alteration of polycyclic aromatic hydrocarbons. Nature 343: 728-731.

Shock EL, Schulte M. 1993. Reply to the comment by S. L. Miller and J. L. Bada on "Summary and implications of reported amino acid concentrations in the Murchison meteorite." Geochim Cosmochim Acta 57: 3475-3477.

Shock EL, Schulte M. 1998. Organic synthesis during fluid mixing in hydrothermal systems. J Geophys Res 103: 28513-28528.

Sleep NH. 2010. The Hadean-Achaean environment. Cold Spring Harb Perspect Biol 2: a002527.

Sleep NH, Zahnle KJ. 2001. Carbon dioxide cycling and implications for climate on ancient Earth. J Geophys Res 106: 1373-1399.

Sleep NH, Zahnle KJ, Neuhoff PS. 2001. Initiation of clement surface conditions on the earliest Earth. Proc Nat Acad Sci 98: 3666-3672.

Stribling R, Miller SL. 1987. Energy yields for hydrogen cyanide and formaldehyde syntheses: The HCN and amino acid concentrations in the primitive ocean. Origins Life 17: $261-273$.

Sugita S, Schultz P. 2009. Efficient cyanide formation due to impacts of carbonaceous bodies on a planet with a nitrogen-rich atmosphere. Geophys Res Lett 36: L20204.

Summons RE, Bradley AS, Jahnke LL, Waldbauer JR. 2006. Steroids, triterpenoids and molecular oxygen Philosophical Transactions. Royal Society B-Biological Sciences 361: 951-968.

Tian F, Toon O, Pavlov A, Sterck De H. 2005. A hydrogenrich early Earth atmosphere. Science 308: 1014-1017.
Tyburczy JA, Frisch B, Ahrens TJ. 1986. Shock-induced volatile loss from a carbonaceous chondrite Implications for planetary accretion. Earth Planet Sci Lett 80: 201-207.

Urey HC. 1951. The origin and development of the earth and other terrestrial planets. Geochim Cosmochim Acta 1: 209-277.

Urey HC. 1952a. The origin and development of the earth and other terrestrial planets: A correction. Geochim Cosmochim Acta 2: 263-268.

Urey HC. 1952b. On the early chemical history of the earth and the origin of life. Proc Nat Acad Sci 38: 351-363.

Visconti G. 1975. The exospheric temperature of a primitive terrestrial atmosphere with evolving oxygen content. J Atmos Sci 32: 1631-1637.

Wächtershäuser G. 1992. Groundworks for an evolutionary biochemistry: The iron-sulfur world. Prog Biophys Molec Biol 58: 85-201.

Wänke H. 1981. Constitution of the terrestrial planets. Phil Trans R Soc London A303: 287-302.

Wen JS, Pinto JP, Yung YL. 1989. Photochemistry of CO and $\mathrm{H}_{2} \mathrm{O}$ : Analysis of laboratory experiments and applications to the prebiotic Earth's atmosphere. J Geophys Res 94: 14957-70.

Whittet DC. 1997. Is extraterrestrial organic matter relevant to the origin of life on Earth? Orig Life Evol Biosph 27: 249-62.

Zahnle KJ. 1986. Photochemistry of methane and the formation of hydrocyanic acid (HCN) in the Earth's early atmosphere. J Geophys Res 91: 2819-2834.

Zahnle KJ. 1990. Atmospheric chemistry by large impacts. In Global Catastrophes in Earth History. V. Sharpton, P. Ward, Eds., GSA Special Paper. 247: 271-288.

Zahnle KJN, Arndt N, Cockell C, Halliday A, Nisbet E, Selsis F, Sleep NH. 2006. Emergence of a habitable planet. Space Sci Rev 129: 35-78.

Zahnle KJ, Kasting JF, Pollack JB. 1988. Evolution of a steam atmosphere during Earth's accretion. Icarus 74: 62-97.

Zahnle K, Mac Low M-M, Lodders K, Fegley B. 1995. Sulfur chemistry in the wake of Comet ShoemakerLevy 9. Geophys Res Lett 22: 1593-1596.

Zahnle KJ, Walker JGG. 1982. Evolution of solar ultraviolet luminosity. Rev Geophys Space Phys 20: 280-292. 


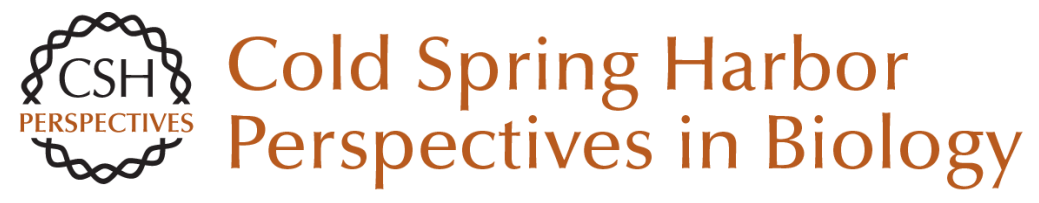

\section{Earth's Earliest Atmospheres}

Kevin Zahnle, Laura Schaefer and Bruce Fegley

Cold Spring Harb Perspect Biol 2010; doi: 10.1101/cshperspect.a004895 originally published online June 23, 2010

\section{Subject Collection The Origins of Life}

\section{Constructing Partial Models of Cells} Norikazu Ichihashi, Tomoaki Matsuura, Hiroshi Kita, et al.

Ribonucleotides John D. Sutherland

Deep Phylogeny--How a Tree Can Help

Characterize Early Life on Earth Eric A. Gaucher, James T. Kratzer and Ryan N. Randall

Cosmic Carbon Chemistry: From the Interstellar Medium to the Early Earth Pascale Ehrenfreund and Jan Cami

Origin and Evolution of the Ribosome George E. Fox

Planetary Organic Chemistry and the Origins of Biomolecules Steven A. Benner, Hyo-Joong Kim, Myung-Jung Kim, et al.

Mineral Surfaces, Geochemical Complexities, and the Origins of Life

Robert M. Hazen and Dimitri A. Sverjensky

Historical Development of Origins Research Antonio Lazcano
The Hadean-Archaean Environment Norman H. Sleep

An Origin of Life on Mars Christopher P. McKay

Primitive Genetic Polymers Aaron E. Engelhart and Nicholas V. Hud

Membrane Transport in Primitive Cells Sheref S. Mansy

The Origins of Cellular Life Jason P. Schrum, Ting F. Zhu and Jack W. Szostak

From Self-Assembled Vesicles to Protocells Irene A. Chen and Peter Walde

The Origin of Biological Homochirality Donna G. Blackmond

Earth's Earliest Atmospheres Kevin Zahnle, Laura Schaefer and Bruce Fegley

For additional articles in this collection, see http://cshperspectives.cshlp.org/cgi/collection/

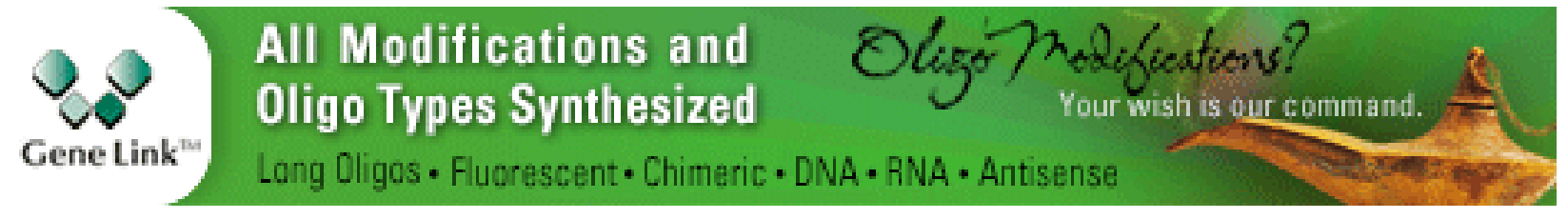

